\title{
IGF2BP3 functions as a potential oncogene and is a crucial target of miR-34a in gastric carcinogenesis
}

\author{
Yuhang Zhou ${ }^{1,2,3 \dagger}$, Tingting Huang ${ }^{1,2,3,4 \dagger}$, Ho Lam Siu ${ }^{1 \dagger}$, Chi Chun Wong ${ }^{2}$, Yujuan Dong ${ }^{2}$, Feng Wu' ${ }^{1}$ Bin Zhang ${ }^{5}$, \\ William K. K. Wu ${ }^{2,6}$, Alfred S. L. Cheng ${ }^{4,7}$, Jun Yu, $2,4,8$, Ka Fai To ${ }^{1,2,3,4^{*}}$ and Wei Kang ${ }^{1,2,3,4^{*}}$
}

\begin{abstract}
Background: Gastric cancer (GC) is one of the frequent causes of cancer-related death in eastern Asian population. IGF2BP2 lists in the top rank up-regulated genes in GC, but its functional role is unclear.

Method: The expression of IGF2BP3 in GC cell lines and primary samples was examined by qRT-PCR and Western blot. The biological role of IGF2BP3 was revealed by a series of functional in vitro studies. Its regulation by microRNAs (miRNAs) was predicted by TargetScan and confirmed by luciferase assays and rescue experiments.

Results: IGF2BP3 ranked the No.1 of the up-regulated genes by expression microarray analysis in GC cell lines. The expression level of IGF2BP3 was observed in GC tissues comparing with non-tumorous gastric epitheliums. The up-regulated IGF2BP3 expression was associated with poor disease specific survival. IGF2BP3 knockdown significantly inhibited cell proliferation and invasion. Apart from copy number gain, IGF2BP3 has been confirmed to be negatively regulated by tumor-suppressive miRNA, namely miR-34a. The expression of miR-34a showed negative correlation with IGF2BP3 mRNA expression in primary GC samples and more importantly, re-overexpression of IGF2BP3 rescued the inhibitory effect of miR-34a.

Conclusion: We compressively revealed the oncogenic role of IGF2BP3 in gastric tumorigenesis and confirmed its activation is partly due to the silence of miR-34a. Our findings identified useful prognostic biomarker and provided clinical translational potential.
\end{abstract}

Keywords: Gastric cancer, IGF2BP3, miR-34a

\section{Background}

Gastric cancer (GC) is one of the most prevalent malignancies worldwide. Accordingly, its incidence ranks the 4th in men and 5th in women while it causes the 3rd cancer-related death for men and 5th for women [1]. Although the incidence appears to decrease in recent years, the mortality still remains high, which may due to the delayed diagnosis and the lack of effective treatment. Its occurrence and development often arise from the interaction between internal genetic heterogeneity and multiple external risk factors, such as Helicobacter Pylori

\footnotetext{
*Correspondence: kfto@cuhk.edu.hk; weikang@cuhk.edu.hk

${ }^{\dagger}$ Equal contributors

'Department of Anatomical and Cellular Pathology, State Key Laboratory in Oncology in South China, Prince of Wales Hospital, The Chinese University of Hong Kong, Hong Kong, SAR, People's Republic of China

Full list of author information is available at the end of the article
}

infection and high-salt diet [2]. For decades, this severe disease has attracted public attention. In 1965, Lauren P identified two types of GC, diffuse and intestinal, based on different histological features [3], which has been widely used in clinical pathology since then. Until 2010, another histological classification was suggested by World Health Organization (WHO): tubular, papillary, mucinous and poorly cohesive (including signet ring cell carcinoma), plus uncommon histologic variants [4]. In 2014, The Cancer Genome Atlas (TCGA) proposed a novel characterization which was built upon the molecular mechanisms, and this classification leads to a brand new insight and an in-depth understanding of GC [5].

Many new emerging technologies are employed in GC research including expression microarray. By screening the putative dysregulated genes achieved by expression 
microarray analysis in nine GC cell lines, we found IGF2BP3 (Insulin-like growth factor-2 mRNA-binding protein 3) listing in the No.1 rank of the up-regulated genes.

IGF2BP3, also known as IMP3, belongs to a conserved IGF2 mRNA-binding protein family. IGF2BP3 was first identified due to its high abundance in pancreatic carcinoma [6]. After its initial identification, IGF2BP3 has soon been explicated to be a mainly over-expressed member among the family in various tumor types, such as squamous cell carcinoma [7], lung cancer [8], melanoma [9], colon cancer [10], liver cancer [11]. And the aberrant upregulation implicated its potential oncogenic role in tumorigenesis. Furthermore, accumulating evidences demonstrated that IGF2BP3 represented a promising biomarker in different cancers, such as colon cancer [12] and GC [13]. However, knowledge of its function and regulation in GC is still quite limited.

High expression of IGF2BP3 mRNA but with low copy number gain rate, suggested that post-transcriptional regulation might play an important role for the IGF2BP3 upregulation in GC. By bioinformatic analysis, we found IGF2BP3 might be regulated by miR-34a (www.microrna.org), which was listed in the relative top rank. microRNAs (miRNAs) has been thought to be new regulators of gene expression through binding to the 3' untranslated regions (UTRs) of the targeted mRNAs [14], and then degrade or translationally inhibit those targeted mRNAs. Deviant expressions of miRNAs were detected in various human malignancies [15], and the aberrant expression is always correlated with oncogenesis [16, 17].

Thus in current study, we will firstly investigate the basic expression and functional role of IGF2BP3 in GC. Secondly, we will comprehensively reveal the expression regulation of IGF2BP3 by miR-34a in GC and detect their expression correlation in primary samples. Finally, the clinical correlation and survival-prediction significance of these potential biomarkers will be revealed. Collectively, we aim to deeply explore the molecular mechanism of up-regulated IGF2BP3 in gastric tumorigenesis and offer a translational potential for clinical intervention of GC.

\section{Methods}

\section{GC cell lines and primary gastric tumor samples}

Human GC cell lines (MKN1, MKN7, MKN28, MKN45, SNU1, SNU16, AGS, KatoIII, NCI-N87, MGC-803, SGC-7901, TMK-1) and immortalized gastric epithelial cells (GES-1 and HFE-145) were described previously [18]. Cells were cultured at $37{ }^{\circ} \mathrm{C}$ in humidified air atmosphere containing 5\% CO2 in RPMI 1640 (GIBCO, Grand Island, NY) medium supplemented with $10 \%$ fetal bovine serum (GIBCO). A cohort of 247 formalin-fixed paraffin embedded tissues of GCs diagnosed between
1999 and 2006 in the Prince of Wales Hospital, Hong Kong was retrieved. Ethical approval was obtained from the Joint Chinese University of Hong Kong-New Territories East Cluster Clinical Research Ethics Committee.

\section{RNA extraction and quantitative real-time polymerase chain reaction (qRT-PCR)}

Cultured cells were harvested for extracting total RNA with TRIzol reagent (Invitrogen, Carlsbad, CA). cDNA synthesis was performed with a High-Capacity cDNA Reverse Transcription Kits (Applied Biosystems, Carlsbad, CA). The variations of mRNA expression of related genes were quantified by qRT-PCR and primers were listed as following: IGF2BP3 (sense: AGT TGT TGT CCC TCG TGA CC; anti-sense: GTC CAC TTT GCA GAG CCT TC); B2M (sense: ACT CTC TCT TTC TGG CCT GG; anti-sense: ATG TCG GAT GGA TGA AAC CC). The protocol of qRT-PCR was described in a previous study [19]. For microRNA expression detection, miR-34a expression in GC was detected by Taqman miRNA assays, and they were used to quantify the levels of mature miR-34a (Assay ID: \#4427975, Life Technologies). The relative expression level of miR-34a was normalized by RNU6B expression (Assay ID: \#001093). 7500 Fast Real-Time System (Applied Biosystems) was used for the $\mathrm{qPCR}$ reaction. And the reaction system was incubated at $95{ }^{\circ} \mathrm{C}$ for $30 \mathrm{~s}$, followed by 40 cycles of $95{ }^{\circ} \mathrm{C}$ for $8 \mathrm{~s}$ and $60{ }^{\circ} \mathrm{C}$ for $30 \mathrm{~s}$.

\section{Protein extraction and western blot analysis}

The protein extraction and western blot analysis protocol were described in our previous study [20]. The primary antibodies detected IGF2BP3 (\#07-104) was from Merck Millipore. Other primary antibodies were from Cell Signaling (Danvers, MA) including p21 (\#2946), p27 (\#2552), p-Rb (Ser807/811) (\#9308), cleaved-PARP (Asp214) (\#9541), Cyclin D3 (\#2936), CDK4 (\# 12790), CDK6 (\#3136) and GAPDH (\#2118). The secondary antibodies were anti-Mouse IgG-HRP (Dako, 00049039, 1:30000) and anti-Rabbit IgG-HRP (Dako, 00028856, 1:10000).

\section{Immunohistochemistry}

Immunohistochemistry was to conduct tissue microarray within a $4 \mu \mathrm{m}$-thick section of each clinical sample using Ventana NexES automated Stainer (Ventana Corporation). All sections were performed microwaving in EDTA antigen retrieval buffer after de-waxing in xylene and graded ethanol. The IGF2BP3 primary antibody (1:100, 07-104) was from Merck Millipore. The cytoplasmic expression of IGF2BP3 was evaluated according to the proportion of tumor cells with intensity of cytoplasmic staining [20]. 
miRNA and siRNA transfection for functional assays The miRNA precursor miR-34a (PM11030) and scramble control (AM17110) were commercially available from Life Technologies. siIGF2BP3-1 (SI03230759) and silGF2BP3-2 (SI04234167) were obtained from Qiagen (Valencia, CA). Lipofectamine 2000 Transfection Reagent (Invitrogen) was used for all transfection assays. The cell proliferation experiments, colony formation assays in monolayer, cell invasion assays, flow cytometry analysis for cell cycle distribution have been described in our previous work [21]. The experiments were repeated in triplicate to obtain standard deviations.

\section{Luciferase activity assays}

The putative miR-34a binding site in IGF2BP3 3'UTR of was subcloned into pMIR-REPORT Vector (Ambion). The oligonucleotides that encompass the miR-34a recognition site and the oligonucleotides which contain the mutated binding site were listed in Additional file 1: Table S1. Prior to digestion and subcloning, oligonucleotides were annealed in $30 \mathrm{mmol} / \mathrm{L}$ HEPES buffer that contains $100 \mathrm{nmol} / \mathrm{L}$ potassium acetate and $2 \mathrm{mmol} / \mathrm{L}$ magnesium acetate [22]. The firefly luciferase constructs were co-transfected with Renilla luciferase vector control into MGC-803 cells. Dual luciferase reporter assays (Promega, Madison, WI) were performed $24 \mathrm{~h}$ after transfection.

\section{Treatment of cell lines with 5-Aza and TSA}

AGS, MKN1, NCI-N87 and MGC-803 were treated with demethyltransferase inhibitor (5-Aza, Sigma, St Louis, $\mathrm{MO})$ and histone-deacetylase inhibitor trichostatin A (TSA, Sigma) [23]. Cells were incubated with $10 \mu \mathrm{M} 5$ Aza for $72 \mathrm{~h}$ in 5-Aza group, while in TSA group, cells were treated with $100 \mathrm{nM}$ TSA for $24 \mathrm{~h}$. As for the combination treatment group, cells were treated with 5-Aza for $96 \mathrm{~h}$ and $100 \mathrm{nM}$ TSA was added into the culture medium in the last $24 \mathrm{~h}$. Equal amount of vehicle DMSO (Sigma) was used in negative control groups.

\section{In vivo tumorigenicity model}

MGC-803 cells $\left(10^{7}\right.$ cells suspended in $0.1 \mathrm{ml}$ PBS) were transfected with miR-34a or scramble control then were injected subcutaneously into the left and right dorsal flank of 4-week old Balb/c nude mice respectively. Diameters of tumors were measured and documented each 5 days with a total of 25 days. Tumor volume $\left(\mathrm{mm}^{3}\right)$ was accessed by measuring the longest and shortest diameter of the tumor and calculating as follows: volume $=(\text { shortest diameter })^{2} \times($ longest diameter $) \times 0.5$. All animal handling and experimental procedures were approved by Department of Health in Hong Kong.

\section{Rescue experiments}

For the rescue experiments, AGS and MKN28 cells were first transfected with miR-34a precursor or negative control respectively. After 24 h incubation, IGF2BP3 expression plasmid (\#19879, Addgene) together with empty vector (pcDNA3.1, Life Technologies) were transfected to the cells using FuGENE HD Transfection Reagent (Roche, Nutley, NJ). After another $24 \mathrm{~h}$, cells were harvested for functional study (MTT proliferation, monolayer colony formation, and cell invasion assays). The in vivo rescue experiments were performed using MGC-803 cells [24].

\section{Statistical analysis}

The Student $T$ test was used to compare the differences in functional differences between siIGF2BP3 and siScramble control transfected cells. It is also used to compare the biological behavior between miR-34a transfected cells and scramble miRNA transfectant counterparts. Nonparametric Pearson Chi-Square test was used to evaluate the correlation between IGF2BP3 expression and selected clinicopathologic parameters. Kaplan-Meier method was used to estimate the survival rate for each parameter and the equivalences of the survival curve were examined by log-rank statistics. For those parameters were found statistically significant in the univariate survival analysis $(P<0.05)$, the Cox proportional hazards model was employed to further evaluate them for multivariate survival analysis. All statistical analysis was performed by SPSS software (version 22.0; SPSS Inc). A two-tailed $P$-value of less than 0.05 was considered statistically significant and the $P$-value less than 0.001 was considered highly significant.

\section{Results}

IGF2BP3 is highly expressed in GC

By gene expression microarray analysis in nine GC cell lines (Additional file 2: Table S2), IGF2BP3 was found to be the most up-regulated gene in the top ten list (Fig. 1a). Consistently, both mRNA and protein expression of IGF2BP3 were up-regulated in most of the GC cell lines comparing with immortalized gastric epithelium cell line (GES-1) (Fig. 1b). In primary samples, reports from GENT dataset manifested that IGF2BP3 showed a dramatically overexpression in 351 GC tissues when compared with the normal gastric tissues $(P<0.01$, Fig. 1c) [25]. In addition, according to a published dataset NCBI/GEO/GSE63089 [26], IGF2BP3 was demonstrated to be highly expressed in GC samples compared with adjacent non-tumorous tissues $(n=45, P<0.001$, Fig. $1 d)$. Moreover, based on TCGA cohort, IGF2BP3 showed significantly up-regulated in both intestinal- and diffuse- types of GC when compared with normal control $(P<0.001$, Fig. 1e). In particular, when it 

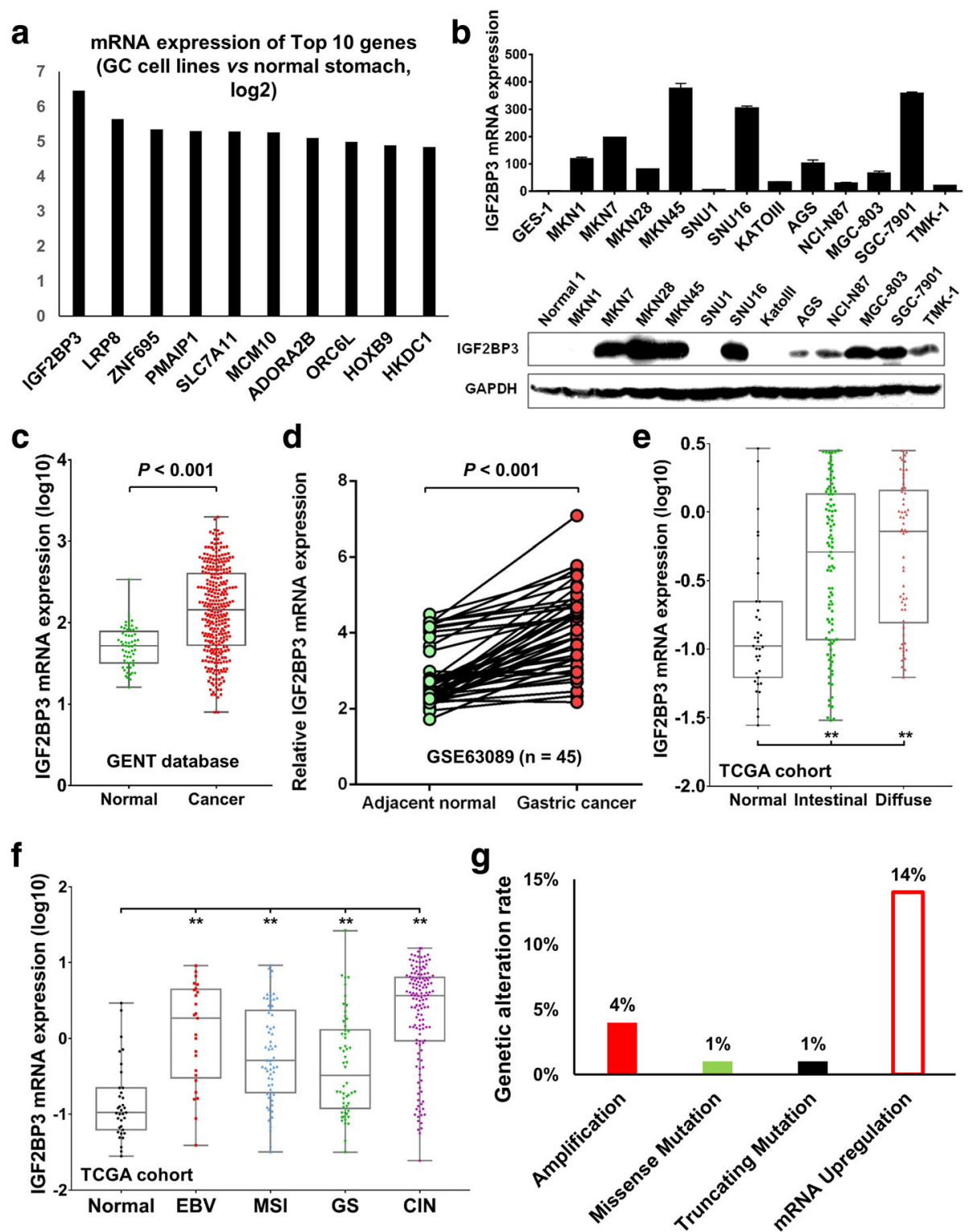

Fig. 1 IGF2BP3 is up-regulated in GC. a Top ten most up-regulated genes from gene expression microarray analysis in nine GC cell lines. IGF2BP3 ranked the top one among the list. $\mathbf{b}$ The mRNA and protein expression of IGF2BP3 in 12 GC cell lines compared with immortalized gastric epithelium cell line GES-1. c IGF2BP3 was highly expressed in 311 GC samples compared with normal gastric tissues (from http://medical-genome.kribb.re.kr/ GENT/, $P<0.001$ ). $\mathbf{d}$ Increased expression of IGF2BP3 in primary gastric tumors compared with adjacent non-tumorous tissues (NCBI/GEO/GSE63089, $P<0.001$ ). e mRNA expression of IGF2BP3 in intestinal and diffuse type GC (Lauren classification) (TCGA cohort, $n=193 ; * *, P<0.001) \mathbf{f}$ IGF2BP3 mRNA expression in four molecular subtypes of GC (TCGA cohort, $n=313 ;{ }^{* *}, P<0.001$ ). $\mathbf{g}$ Proportion of genetic alterations of IGF2BP3 (from http://www.cbioportal.org/; $n=258$ )

came to the molecular characterization proposed by TCGA [5], high level of IGF2BP3 was observed frequently in the subtype of chromosomal instability (CIN) and EBV positive GC, while its level was relative lower in genomically stable (GS) subtype (Fig. 1f). For deep investigation of the regulation mechanisms of IGF2BP3 in GC, the genomic alteration of IGF2BP3 in TCGA cohort was analyzed by cBioPortal (www.cbioportal.org/) [27, 28], including copy number changes, somatic mutation and mRNA upregulation. It was found that $18 \%$ cases $(47 / 258)$ have at least one alteration of IGF2BP3. And the rate of mRNA upregulation counted for $14 \%$ cases (Fig. 1g). Although the copy number gain showed positive correction with IGFBP3 mRNA expression $(P<0.05$, Additional file 3: Figure $\mathrm{S} 1)$, its mRNA upregulated in all GC samples can not merely be explained by copy number change. 


\section{Overexpression of IGF2BP3 correlates with poor survival} in GC

From Kaplan Meier plotter (www.kmplot.com), overexpression of IGF2BP3 was correlated with poor survival of both overall and first progression GC cases $(P=0.018$, overall survival; $P<0.001$, first progression survival; Fig. 2a and Additional file 4: Table S3) [29]. In TCGA cohort, although the $P$-value was not significant, there was still a trend that aberrant richness of IGF2BP3 was associated with unfavorable outcome $(P=0.141$, overall survival; $P=0.078$, recurrence free survival; Fig. $2 b$ ). Subsequently, we conducted immunohistochemistry to elucidate the protein expression of IGF2BP3 in GC tissue microarray. In normal gastric epitheliums, there
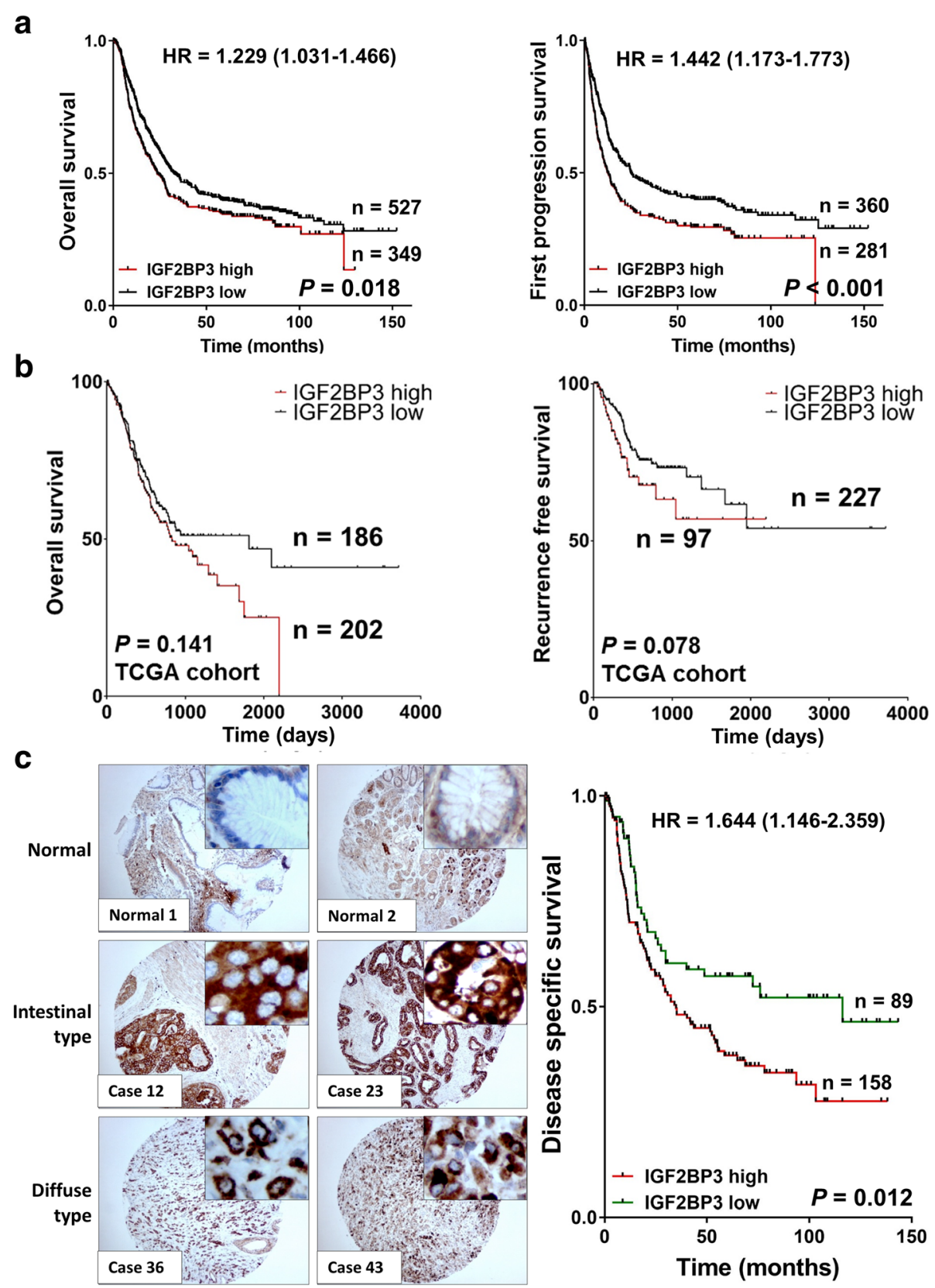

Fig. 2 Overexpression of IGF2BP3 predicts poor prognosis in GC. a Over-expressed IGF2BP3 was related to worse overall outcome and significantly associated with first progression survival in primary GC samples from Kaplan Meier plotter. $\mathbf{b}$ In TCGA cohort, high IGF2BP3 expression showed a non-significance trend to predict unfavorable overall and recurrence free survival. c Left panel, representative immunohistochemistry images of IGF2BP3 in normal gastric epithelium tissues, intestinal-, diffuse type GC samples (original magnification $\times 100$, insertion × 400). IGF2BP3 expression was mainly localized in the cytoplasm. Right panel, Kaplan-Meier plots of disease specific survival according to IGF2BP3 expression status. IGF2BP3 accumulation in cytoplasm (moderate/strong staining) was associated with poor disease specific survival in patients with GC $(P=0.012)$ 
was a negative expression of IGF2BP3. Significantly, a strong cytoplasmic staining was observed in both intestinal- and disuse-types of GC cells (left panel, Fig. 2c), and this strong staining predicted a poor disease specific survival if we classified the samples as two subgroups (negative/week and moderate/strong subgroups, $P=0.012$, right panel, Fig. 2c). The correlations between IGF2BP3 and clinicopathologic parameters in 247 GC samples were summarized in Additional file 5: Table S4. Specifically, IGF2BP3 upregulation was only correlated with $\mathrm{N}$ stage $(P=0.025)$. In univariate analysis, age, diffuse type, high grade, advanced stage, lymph node metastasis and overexpression of IGF2BP3 had a statistical association with poor survival. However, by multivariate Cox regression analysis, only age and advanced stage were two independent factors (Additional file 6: Table S5).

\section{Silence of IGF2BP3 exerts tumor-suppressive effects both in vitro and in vivo}

From the results of GSEA (Gene Set Enrichment Analysis) in a published GC cohort NCBI/GEO/GSE62254 $(n=300)$ [30], IGF2BP3 upregulation was found to have a positive correlation with expression of a common cancer gene set which was defined by a group of Singaporean researchers $(P<0.001)$ [31]. Furthermore, IGF2BP3 was also significantly correlated with cell growth $(P<0.001)$ [32] and cell cycle progression $(P=$ 0.004 , Fig. 3a) [33, 34]. Since IGF2BP3 was expressed abundantly in MKN28 and SGC-7901 cell lines, we conducted siRNA-mediated knockdown experiments to reveal its function in these two cell lines. After treatment of two silGF2BP3s, both mRNA and protein expressions of IGF2BP3 were declined in cells (Fig. 3b). Silencing IGF2BP3 slowed down the rate of cell growth, as indicated in a 4 -day MTT assays $(P<0.001$, Fig. $3 c)$. Monolayer colony formation ability was inhibited after IGF2BP3 knockdown compared with scramble control $(P<0.001$, Fig. $3 d)$. Besides, cell invasive ability was markedly suppressed by silGF2BP3 transfection $(P<0.001$, Fig. 3e). As proliferation-inhibition phenotypes were observed in siIGF2BP3 groups, the associated cell cycle regulators and apoptosis markers were analyzed by Western blot. The phosphorylated Rb (p-Rb), CDK4, CDK6 expression were decreased but p21 and p27 were uniformly up-regulated in IGF2BP3 knockdown cells, supporting the G0/G1-phase cell cycle arrest. Together, knockdown of IGF2BP3 did not induce obvious late apoptosis in MKN28 and SGC-7901 cell (Fig. 3f). Then the transfectants for cell-cycle parameters were analyzed by flow cytometry to validate the Western blot results. As shown in Fig. 3g, MKN28 cells with silGF2BP3 knockdown groups contained a higher percentage of G0/G1 phase cells (52.9 and 54.7\% respectively) compared with siScramble control counterparts (46.7\%). The cell population of G0/G1 phase in IGF2BP3-knockdown SGC7901 cells were increased from siScramble control (56.8\%) to 62.2 and $77.4 \%$ respectively (Fig. $3 g$ ).

\section{IGF2BP3 is a direct target of miR-34a in GC}

In IGF2BP3 3'UTR, the binding site for miR-34a was predicted by miRNA.org (http://www.microrna.org/) with the mirSVR scores of -1.098 (Fig. 4a). miR-34a ranks the top miRNA list that potentially targets IGF2BP3. Both the mRNA and protein expression of IGF2BP3 were found decreased in AGS and MKN28 cells after ectopic expression of miR-34a (Fig. $4 \mathrm{~b}$ and c). To test whether IGF2BP3 was a direct target of miR-34a, we conducted the luciferase experiment. As shown in Fig. 4d, miR-34a inhibited the luciferase activity of construct encompassing the wild type binding site in IGF2BP3 3'UTR, but it had no effect on the construct containing mutated sequence of the binding site (Fig. 4d). This result supported that miR-34a regulated IGF2BP3 expression by directly binding with its 3'UTR. miR-34a showed uniformly down-regulated in all $11 \mathrm{GC}$ cell lines compared with immortalized gastric epithelium cell line HFE-145 (Fig. 4e). However, the expression of miR-34a was not restored after treating the GC cells with 5-Aza or TSA (Fig. 4f), suggesting that epigenetic modification, such as promoter methylation or histone deacetylation, may not play an important role in the regulation of miR34a expression.

\section{miR-34a functions as potential tumor suppressor in GC cells}

To investigate the biological role of miR-34a in GC, ectopic expression of miR-34a precursor in GC cells (MKN28 and SGC-7901) was performed. MTT proliferation assays indicated that overexpression of miR-34a reduced cell proliferation (Fig. 5a) and this inhibitory effect was subsequently validated via monolayer colony formation study (Fig. 5b), with less and smaller colonies found in miR-34a over-expressed group. Moreover, a descending cell invasion was found in the cells with ectopic miR-34a transfection compared with negative control (Fig. 5c). Due to the proliferation inhibition, cell cycle analysis by flow cytometry was conducted. As shown in Fig. 5d, miR-34a increased G0/G1 proportion from 71.9 to $77.6 \%$ in MKN28 cells. In SGC-7901, miR34 a overexpression resulted in $67.8 \%$ proportion of $\mathrm{G} 0 /$ G1 cells when compared to $49.5 \%$ in negative control group (Fig. 5d). The results were further verified by Western blot of cell cycle regulators and apoptosis markers. The expression of $\mathrm{p}-\mathrm{Rb}$ and Cyclin D3 showed decreased but p21 and p27 displayed up-regulated after overexpression of miR-34a in AGS, MKN28 and SGC7901 cell. In addition, miR-34a induced late apoptosis, represented by the activation of cleaved-PARP in all the 


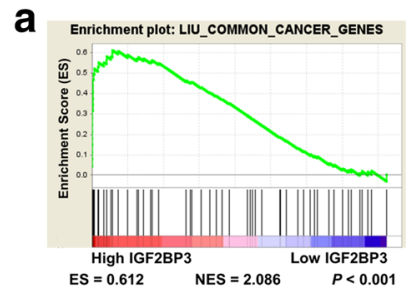

b

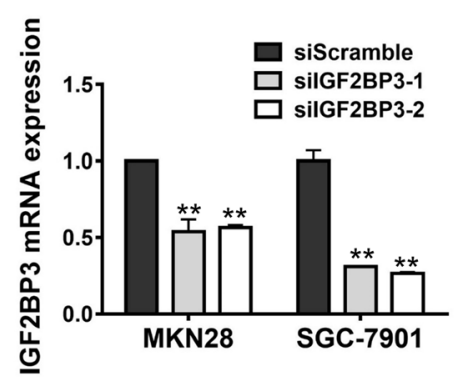

d
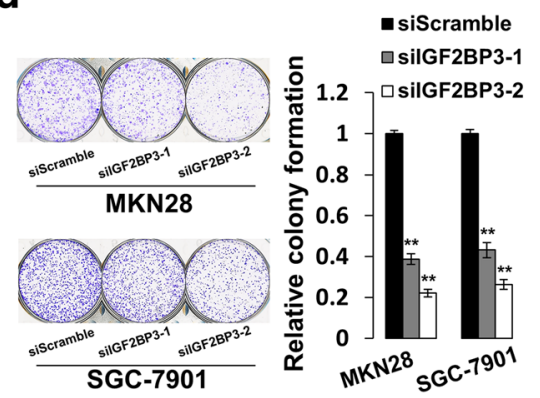

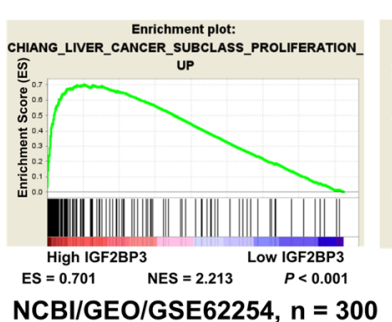

C

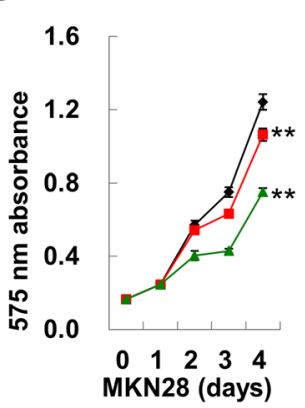

e

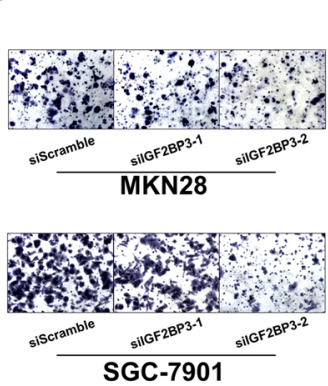

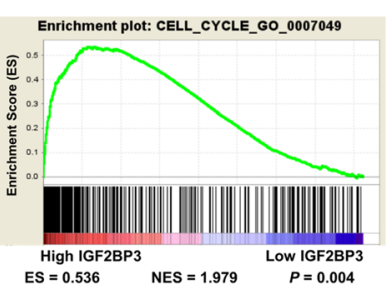

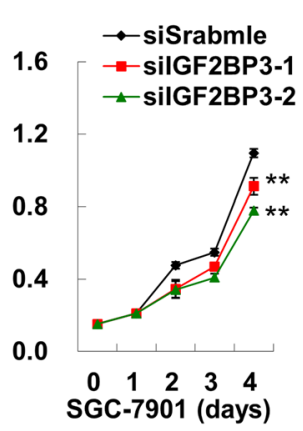

f

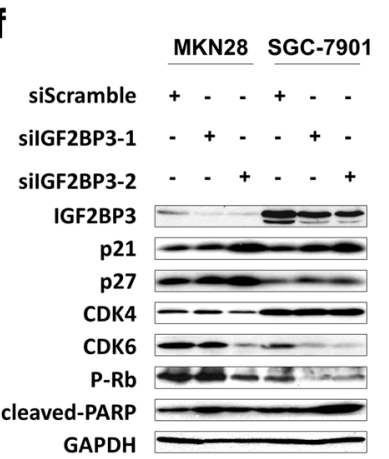

9
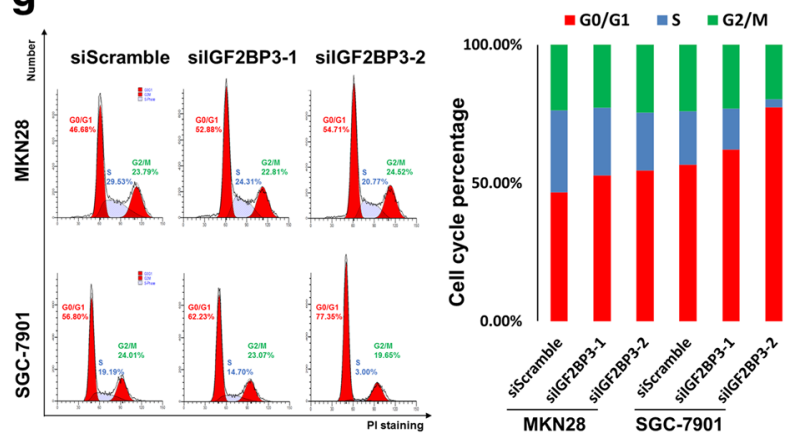

Fig. 3 Silence of IGF2BP3 exerts anti-oncogenic role in GC. a Enrichment plots of gene expression signatures for common cancer genes (LIU_COMMON_CANCER_GENES) $(P<0.001)$, cell proliferation (CHIANG_LIVER_CANCER_SUBCLASS_PROLIFERATION_UP) $(P<0.001)$ and cell cycle progression (CELL_CYCLE_GO_0007049) ( $P=0.004)$ according to IGF2BP3 mRNA expression in a published cohort (NCBI/GEO/GSE62254, $n=300)$. The barcode plot indexed the position of the genes in each gene set. Red and blue colors indicated high and low level of IGF2BP3. ES, enrichment score; NES, normalized enrichment score. $\mathbf{b}$ mRNA expression of IGF2BP3 after siRNA-mediated knockdown in MKN28 and SGC-7901 cells (**, $P<0.001)$. c Knocking down IGF2BP3 reduced cell growth in a 4-day MTT proliferation assay in MKN28 and SGC-7901 cells (**, $P<0.001)$. d Monolayer colony formation of GC cells was suppressed by silGF2BP3 $\left(^{* *}, P<0.001\right)$. e IGF2BP3 knockdown inhibited cell invasive ability $\left.{ }^{* *}, P<0.001\right)$. f Expression of related cell cycle regulators and apoptotic markers by Western blot analysis. CDK4, CDK6 and p-Rb were down-regulated, while p21 and p27 showed uniformly elevated expression in IGF2BP3-depleted cells. $\mathbf{g}$ Flow cytometry analysis of IGF2BP3 knockdown transfectants together with scramble siRNA transfectants as control. Two independent experiments were performed and the representative one was shown in the bar chart 


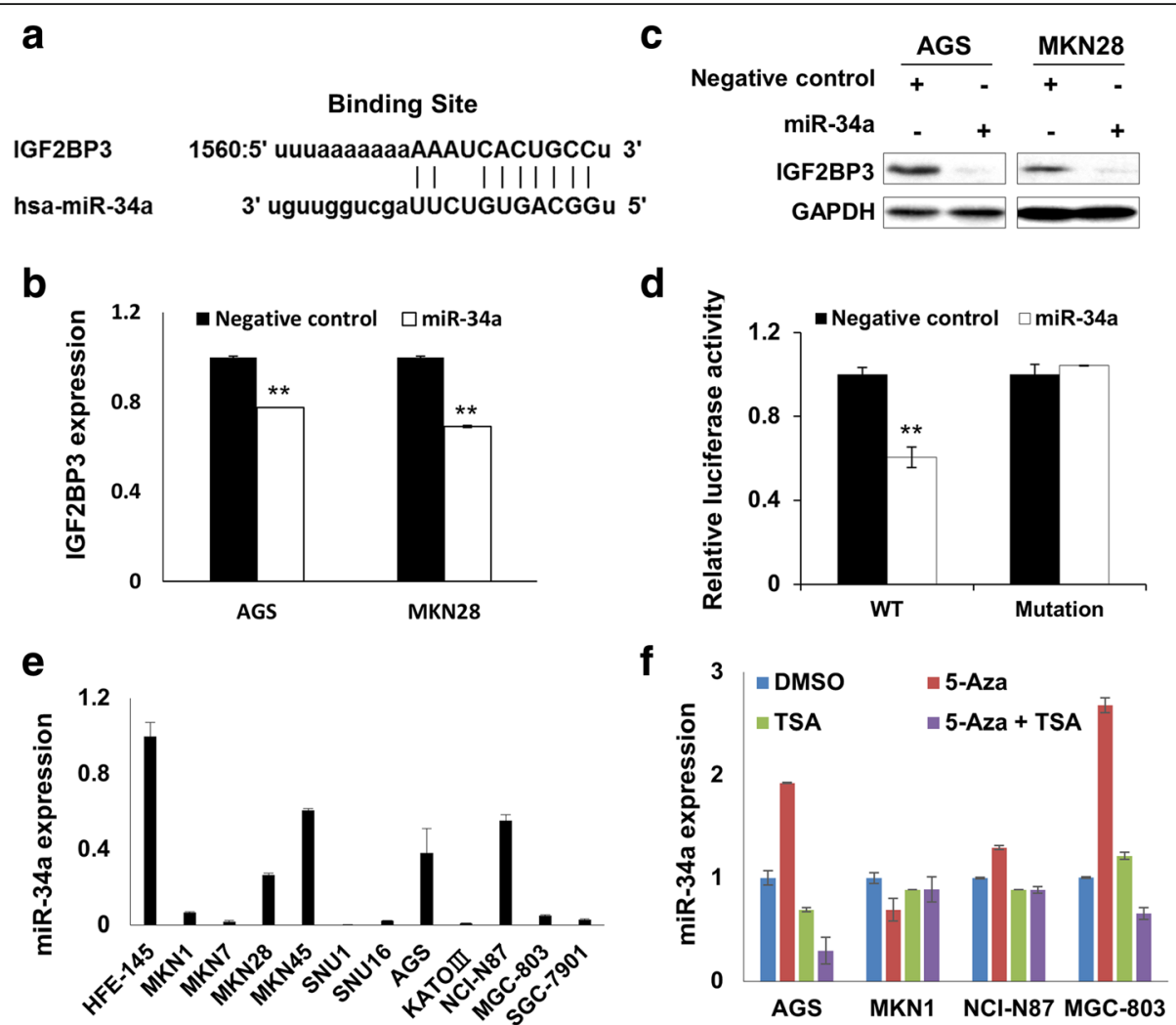

Fig. 4 IGF2BP3 is a direct target of miR-34a in GC. a The putative miR-34a binding site in 3'UTR of IGF2BP3. $\mathbf{b}$ IGF2BP3 mRNA expression was downregulated by ectopic miR-34a expression in AGS and MKN28 cells $(* *, P<0.001)$. c miR-34a overexpression decreased the IGF2BP3 protein expression in GC cells.. d miR-34a inhibited the luciferase activity of constructs encompassing the wild type binding site, but the luciferase activity in the construct containing mutated binding site in IGF2BP3 3'UTR was not affected (WT, wild type of the complementary sequence for seed region; Mutation, the binding site was mutated; **, $P<0.001)$. e miR-34a expression in 11 GC cell lines compared with immortalized gastric epithelium cell HFE-145. f Expression of miR-34a in AGS, MKN1, NCI-N87 and MGC-803 cells after treatment with 5-Aza or TSA respectively

three GC cell lines (Fig. 5e). The effect of miR-34a on in vivo tumor growth was also investigated. MGC803 cells transfected with negative control and miR34 a were subcutaneously injected into 4-week-old nude mice. Tumors grew slower and showed smaller size in miR-34a group than those in the negative control group $(P<0.001$, Fig. 5f).

\section{Downregulation of miR-34a correlates with poor survival in $\mathrm{GC}$}

Apart from the functional study, the expression of miR-34a in primary samples and its clinical correlation were analyzed. In two published cohorts, TCGA $(n=285)$ as well as a Japanese cohort (E-TABM-341, $n=184$ ) [35], a considerably lower expression of IGF2BP3 was observed in diffuse type in contrast with intestinal type GC $(P=0.006$ and $P=0.008$ respectively, Fig. 6a). For molecular characterization of GC, miR-34a expression showed a lower expression in in GS subtype $(P<0.001$, Fig. 6b), suggesting downregulation of miR-34a might strongly be associated with metastasis. Furthermore, downregulation of
miR-34a in GC samples predicted poorer outcome in overall survival $(P=0.024)$ [36], but for recurrence free survival, decreased miR-34a only showed a trend to correlate with poor prognosis $(P=0.098$, Fig. 6c and Additional file 7: Table S6). To further investigate if miR-34a is a crucial regulator of IGF2BP3 in GC, the expression correlation of miR-34a and IGF2BP3 was analyzed in TCGA cohort. As shown in Fig. 6d, there was a negative association between their expression in overall cases $(r=-0.132, n=277, P=0.028)$. Remarkably, when the cohort was re-analyzed according to Lauren classification, a more stringent reverse correlation between miR-34a and IGF2BP3 was observed in intestinal type GC $(r=-0.249, P<0.001)$. These results implicated that IGF2BP3 was modulated by miR-34a in primary GC, especially in intestinal type GC.

\section{IGF2BP3 re-expression rescues the tumor-suppressive function of miR-34a}

Finally, we investigated if the IGF2BP3 was a real functional target of miR-34a in GC by rescue experiments. 

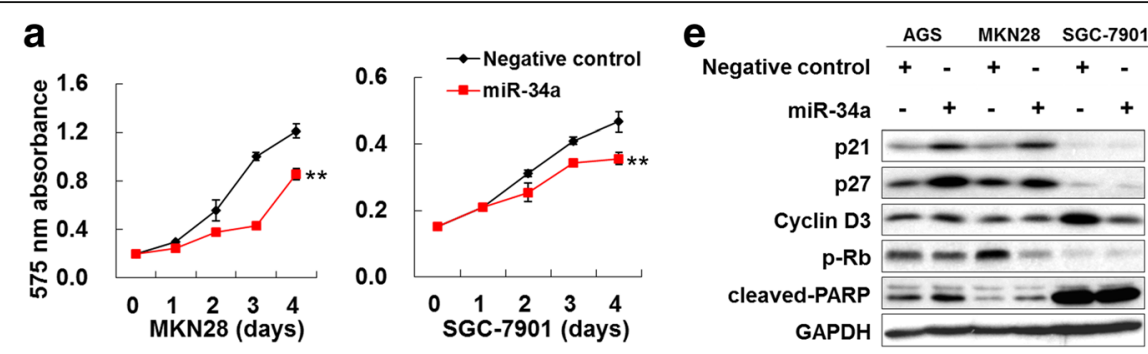

b
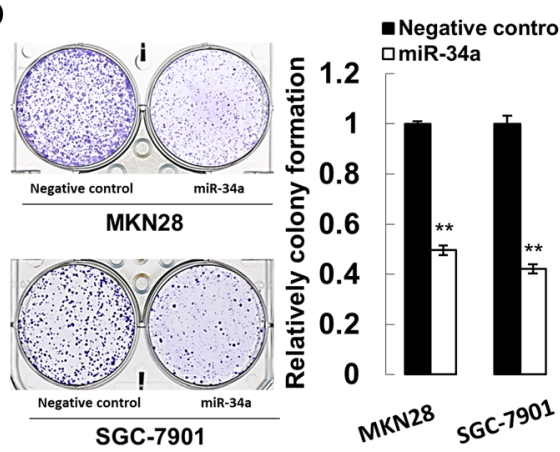

C

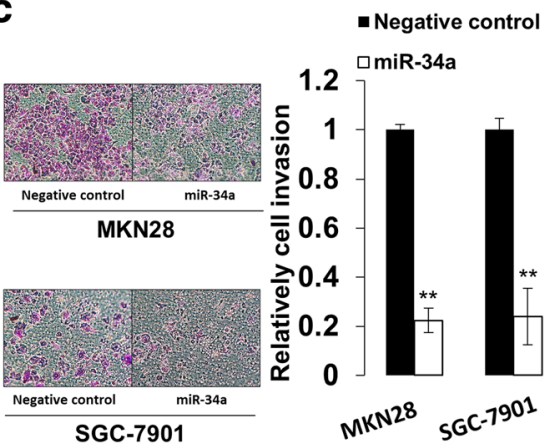

d
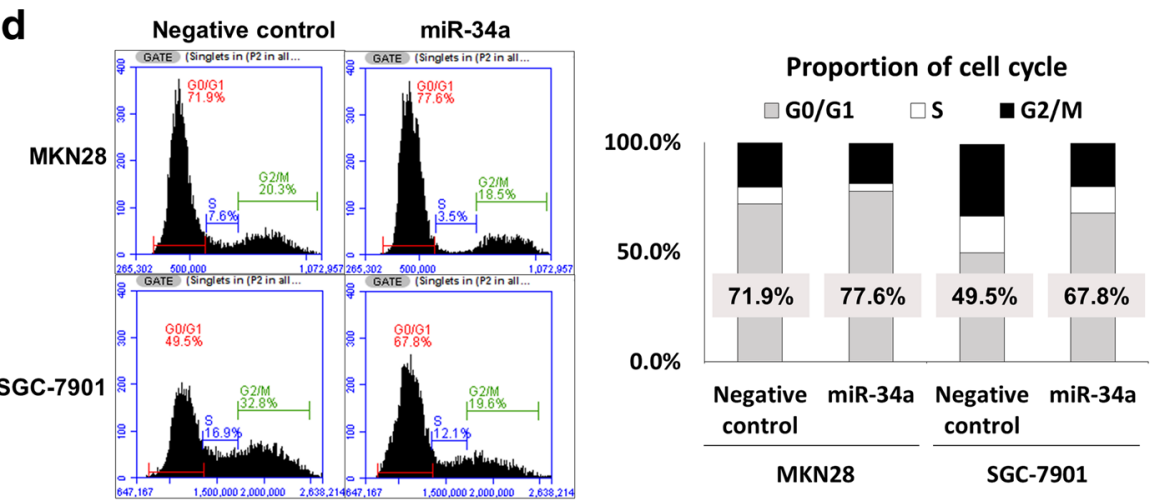

f
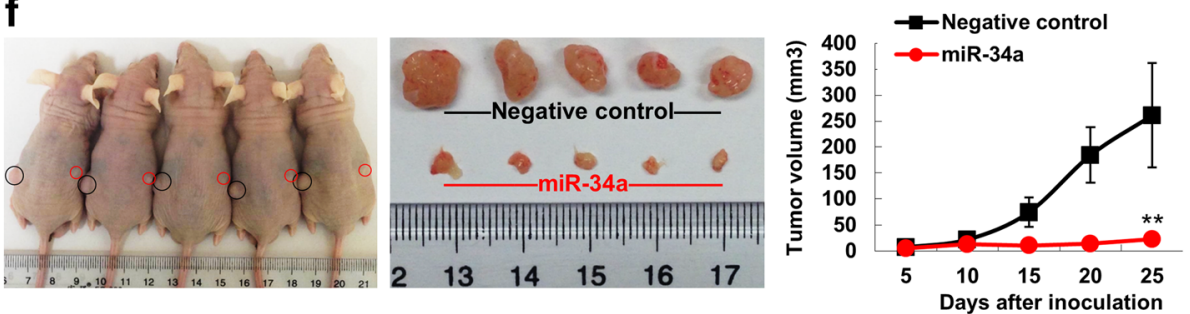

Fig. 5 miR-34a is a tumor-suppressive miRNA. a Overexpressed miR-34a impaired GC cell growth in a 4-day MTT assay in MKN28 and SGC-7901 cells $(* *, P<0.001)$. b Smaller sizes and less numbers of monolayer colonies were detected in miR-34a transfectants compared with negative control group (**, $P<0.001)$. c The cell invasion ability was partly abolished after treatment with miR-34a $(* *, P<0.001)$. The invaded cells from the matrigel were counted in three random vision fields for getting standard deviations. $\mathbf{d}$ Cell cycle analysis by flow cytometry revealed that ectopic expression of miR-34a raised the proportion of G0/G1-phase cells. e Western blot analysis of related cell cycle regulators and apoptotic markers. $\mathbf{f}$ miR-34a overexpression in MGC-803 cells inhibited xenograft formation in vivo (**, $P<0.001$ )

Re-expression efficiency of IGF2BP3 was first verified by Western blot analysis (Fig. 7a). Both MTT proliferation and colony formation assays explicated growthinhibition effect of miR-34a was partly alleviated by IGF2BP3 re-overexpression (Fig. 7b and c). In addition, re-expression of IGF2BP3 partly restored the impaired cell invasion ability in miR-34a treated GC cells (Fig. 7d). Importantly, in vivo experiments demonstrated that reexpressed IGF2BP3 partly abolished the anticarcinogenic function of miR-34a, further emphasizing that IGF2BP3 was the bona fide functional target of miR-34a in GC (Fig. 7e). 

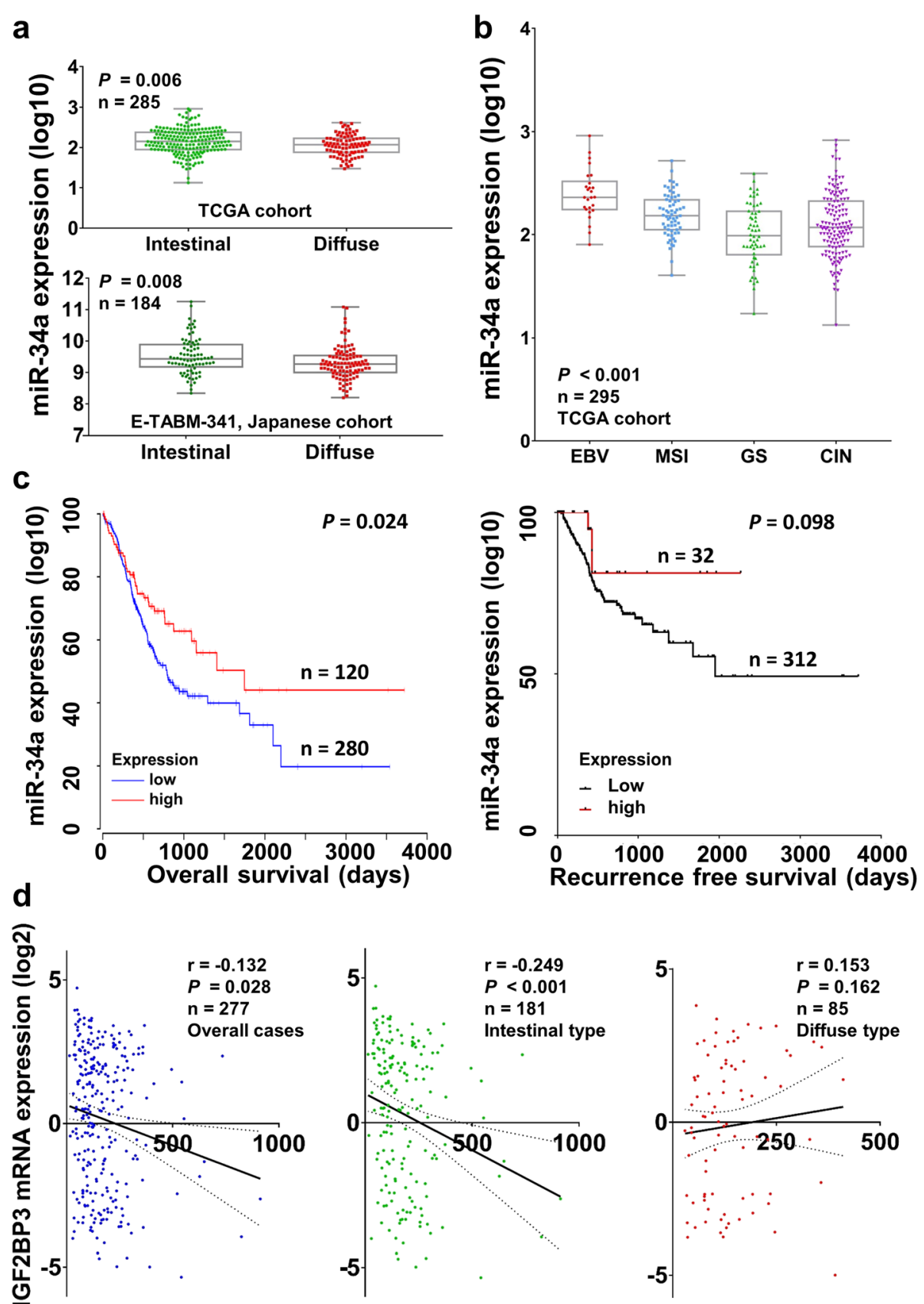

miR-34a expression (reads per million miRNA mapped, TCGA cohort)

Fig. 6 Low expression of miR-34a correlates with worse clinical outcome in GC patients. a A lower expression of IGF2BP3 was detected in primary diffuse type of GC compared with intestinal type GC in a published Japanese cohort (E-TABM-341, $n=184, P=0.008)$ and TCGA cohort $(n=285$, $P=0.008)$. $\mathbf{b}$ The expression of miR-34a in four molecular subtypes of GC (TCGA cohort, $n=295, P<0.001)$. $\mathbf{c}$ In TCGA cohort, downregulation of miR-34a predicted a shorter overall survival in primary GC samples $(P=0.024)$. However for recurrence free survival, only an unfavorable trend was detected in low-expression miR-34a group $(P=0.098)$. $\mathbf{d}$ miR-34a expression showed inversely correlated with IGF2BP3 mRNA level in primary samples of TCGA cohort $(r=-0.132, n=277, P=0.028)$. In intestinal type GC, the negative correlation was more stringent $(r=-0.249, n=181, P<0.001)$

\section{Discussion}

IGF2BP3, contains a structure of two N-terminal RNA recognition motifs (RRM) and four C-terminal messenger ribonucleoprotein $\mathrm{K}$ homology $(\mathrm{KH})$ domains [37]. The $\mathrm{C}$-terminal $\mathrm{KH}$ domains are required for RNA-binding, and this attribute decides the cytoplasmic localization and granular distribution of IGF2BP3 $[38,39]$.

IGF2BP3 has been reported to participate in tumorigenicity in numerous kinds of cancers and its overexpression in tumorous tissues makes it a promising biomarker for 


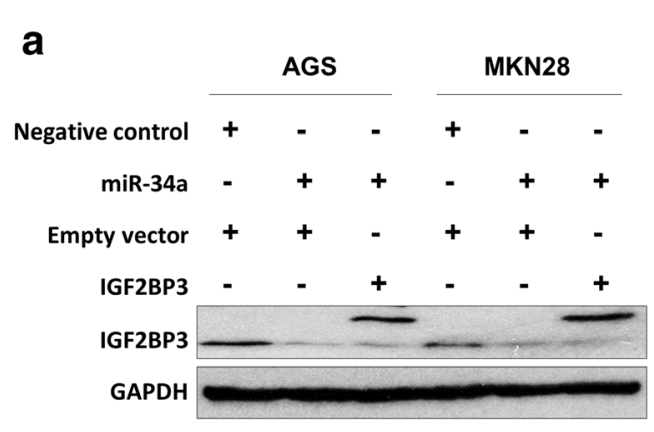

C

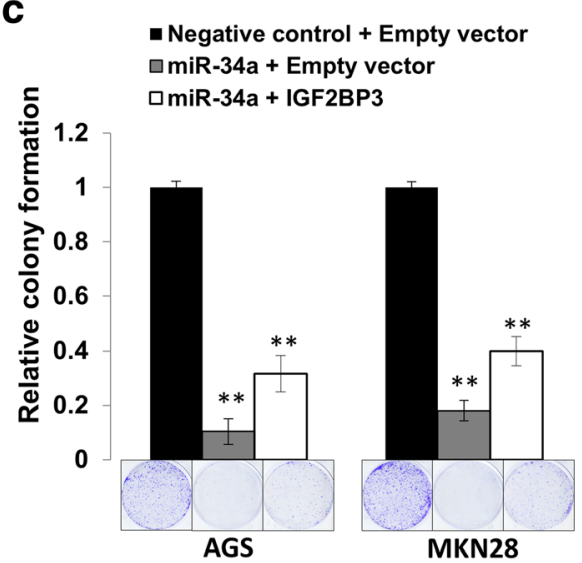

e

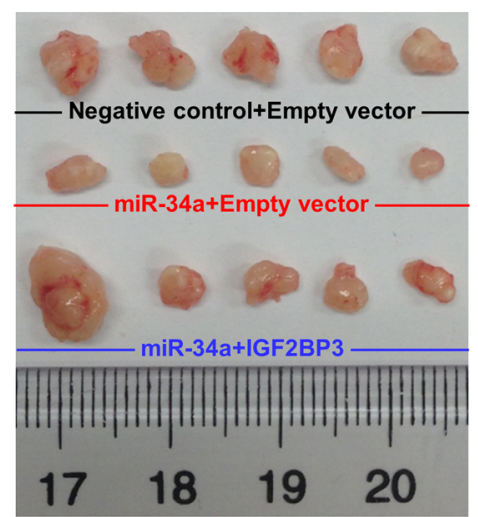

b $\rightarrow$-Negative control+Empty vector

b $\rightarrow$ - miR-34a+Empty vector

$\mp$ miR-34a+IGF2BP3

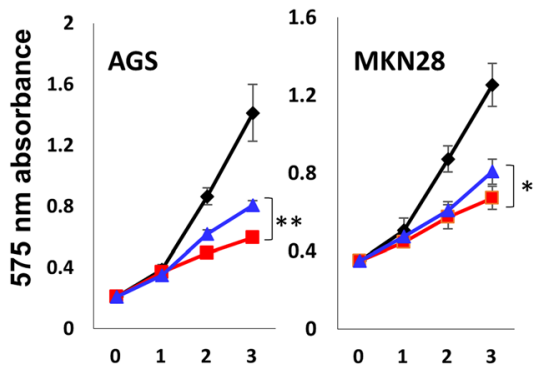

d

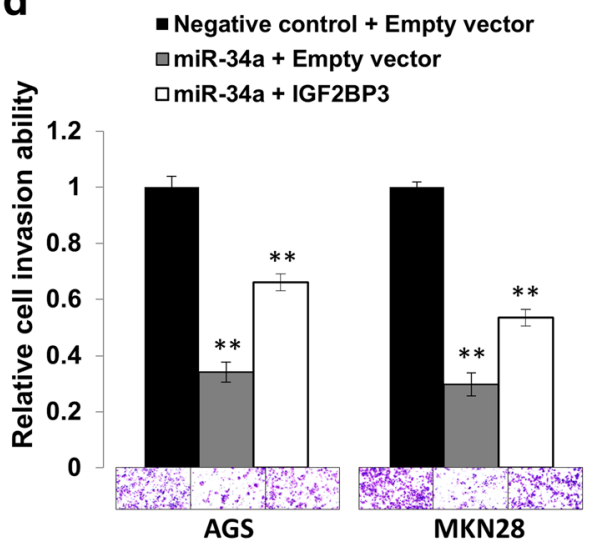

Fig. 7 IGF2BP3 re-expression partly abrogated the inhibitory effect of miR-34a in GC. a Efficiency of IGF2BP3 re-expression was determined by Western blot. b MTT proliferation assay revealed that re-overexpressed IGF2BP3 partly rescued the growth repression of miR-34a $\left({ }^{*}, P<0.05 ;{ }^{* *}, P<0.001\right)$. $\mathbf{C}$ Partial restoration of the suppressed cell growth was observed by monolayer colony formation after IGF2BP3 re-overexpression $\left({ }^{* *}, P<0.001\right)$. d Ectopic expression of IGF2BP3 partly recovered the cell invasion ability impaired by miR-34a (**, $P<0.001$ ). e Re-expressed IGF2BP3 in MGC-803 cells partly revive the tumor volume compared with miR-34a group confirmed by in vivo study $(*, P<0.05)$

diagnosis or prognosis accordingly [40]. The enrichment of IGF2PB3 in human malignancies might promote tumor growth via raising the quantity of IGF2 [41]. Moreover, IGF2BP3 enhanced cell proliferation through synergizing with hnRNPM in the nucleus, leading to an elevated level of cyclins [42]. Recently, IGF2BP3 was believed to, mainly through the let-7 family, boost the expression level of High-mobility group AT-hook 2 (HMGA2) by preventing
miRNA binding [43]. In breast cancer, apart from the capability of elevating the invasive potential [44], IGF2BP3 was also believed to be involved in chemo-resistance by stabilizing the mRNA of breast cancer resistance protein (ABCG2) [45].

There were several reports focusing on IGF2BP3 in $\mathrm{GC}$ in the past years. A group of Japanese scientists suggested IGF2BP3 to be an independent poor prognostic 
marker and an indicator for peritoneal dissemination in GC after surgery [46]. Similarly, merely based on their own clinical cohort, Kim $\mathrm{HJ}$ et al. also indicated that IGF2BP3 predicted worse outcome and malignant effusion among GC patients [13]. Recently, IGF2BP3 was again proposed to be associated with poor survival in Brazilian population [47]. However, all the previous studies failed to investigate the functional role of IGF2BP3 in gastric carcinogenesis. In our study, we provided the first evidence to comprehensively reveal the oncogenic function of IGF2BP3 in GC. Upregulation of IGF2BP3 was detected in both GC cell lines and primary GC samples in our cohort, as well as other published databases. In addition, we described IGF2BP3 expression with molecular classification proposed by TCGA. The IGF2BP3 was uniformly high expressed in all the four subtypes in contrast with normal gastric tissues. This abundance was proved to promote cell growth and invasive ability in GC cell lines via functional assays, which was further confirmed by GSEA results. Moreover, data from flow cytometry demonstrated that IGF2BP3 might play a role in G1 to M phase transition. And a previous work done by Rivera Vargas $\mathrm{T}$ et al. explained that IGF2BP3 protein directly bound with the mRNAs of CCND1/3, together with hnRNPM, to control the expression of CCND1/3 in the nucleus [42].

To further investigate the mechanism of IGF2BP3 upregulation in gastric carcinogenesis, we firstly checked the copy number change and mRNA expression in TCGA cohort. However, more cases with mRNA expression than the cases with copy number gain were detected, we thereby focused on post-transcriptional regulation mechanism, such as dysregulated related miRNAs. After screening and a series validation assays, miR$34 \mathrm{a}$ was confirmed to be the main regulator of IGF2BP3 and their expression showed negative correlation in primary samples, especially in intestinal type GC. Rescue experiments demonstrated that IGF2BP3 is a crucial target of miR-34a in GC because IGF2BP3 reoverexpression partly relieved the tumor-suppressive effect of miR-34a. miR-34a has been identified as a classical tumor suppressive miRNA in variety of malignancies $[48,49]$. Multiple putative targets have been revealed for miR-34a to exert its tumor-suppressive role [50], such as period 1 (Per1) in cholangiocarcinoma [51], NOTCH1 in colon cancer stem cells [52], Hepatocyte nuclear factor $4 \alpha$ (HNF4 $\alpha$ ) in hepatocellular carcinoma [53] and transforming growth factor$\beta$-induced factor 2 (Tgif2) in bone metastasis [54]. It has been also reported that miR-34a enhances the sensitivity of GC cells against cisplatin through PI3K/ $\mathrm{AKT} /$ survivin pathway $[50,55]$. On the other hand, our study suggested the activation of IGF2BP3 in GC is partly due to silence of miR-34a and enriched the target pool of miR-34a. Furthermore, a great number of papers have proposed that miR-34a mimics had therapeutic potential to inhibit cancer progression [56-58].

\section{Conclusions}

In summary, high expression of IGF2BP3 in GC was associated with poor prognosis. Knockdown of IGF2BP3 significantly suppressed its oncogenic role. The upregulation of IGF2BP3 was partly due to the silence of tumor-suppressive miR-34a in some GC samples. Our findings not only clarified the mechanism of IGF2BP3 upregulation in GC but also provided therapeutic target for clinical intervention.

\section{Additional files}

Additional file 1: Table S1. Oligonucleotides used in the luciferase activity experiments. The oligonucleotides were annealed and subcloned into PMIR-REPORT via HindIII and Spel restriction sites. WT (Wild type), full length of the putative miRNA binding site; Mutation, the binding site was mutated. (DOC $34 \mathrm{~kb}$ )

Additional file 2: Table S2. Expression microarray. (XLS $4646 \mathrm{~kb}$ ) Additional file 3: Figure S1. The correlation of IGF2BP3 copy number changes with it mRNA expression in primary GC samples $\left({ }^{*}, P<0.05\right.$; TCGA cohort). (TIF $1399 \mathrm{~kb}$ )

Additional file 4: Table S3. Statistical results of IGF2BP3 survival curve analyzed by KM Plotter (http://kmplot.com) (sig, significantly; Cl, confident interval). (DOCX $14 \mathrm{~kb}$ )

Additional file 5: Table S4. Correlation of IGF2BP3 expression in GC with other clinicopathologic features (significant $P$-value in bold and Italic format). The case number and percentage counted were shown in the table. (DOC $64 \mathrm{~kb}$ )

Additional file 6: Table S5. Univariate and multivariate Cox regression analysis of the association between clinicopathologic characteristics and disease specific survival in patients with gastric adenocarcinoma ( $n=247$, significant $P$-value in bold and Italic format). (DOC $35 \mathrm{~kb}$ )

Additional file 7: Table S6. Statistical results of miR-34a survival curve derived from TCGA (sig, significantly; Cl, confident interval). (DOCX 15 kb)

\section{Abbreviations}

ABCG2: Breast cancer resistance protein; CIN: Chromosomal instability; GC: Gastric cancer; GS: Genomically stable; GSEA: Gene Set Enrichment Analysis; HMGA2: High-mobility group AT-hook 2; HNF4a: Hepatocyte nuclear factor 4a; hnRNPM: Heterogeneous Nuclear Ribonucleoprotein M; IGF2BP3: Insulin-like growth factor-2 mRNA-binding protein 3; KH domains: $\mathrm{K}$ homology domains; miRNA: microRNAs; Per 1: Period 1; RRM: RNA recognition motifs; TCGA: The Cancer Genome Atlas; Tgif2: Transforming growth factor- $\beta$-induced factor 2; UTRs: Untranslated regions; WHO: World Health Organization

\section{Acknowledgements}

We acknowledge the TCGA research Network (http://cancergenome.nih.gov/), The UCSC Cancer Genomics Browser (https://genome-cancer.ucsc.edu/), and $\mathrm{NCl}$ Center for Cancer Genomics Office (http://gdc.nci.nih.gov/) for providing the gastric cancer data set and analysis.

\section{Funding}

This study is supported by General Research Fund (RGC Reference No. CUHK14114414 and CUHK14110016) from The Research Grants Council of Hong Kong.

Availability of data and materials Not applicable. 


\section{Authors' contributions}

KFT and WK designed the experiments, provided direction and guidance on the whole project. YZ, TH, HLS, CCW, YD, FW and BZ conducted the experiments, analyzed the results and performed bioinformatics analysis. YZ, TH and WK drafted the manuscript. WKKW, ASLC and JY reviewed the manuscript and made significant revisions on the drafts. All authors read and approved the final manuscript.

\section{Competing interests}

The authors declare that they have no competing interests.

\section{Consent for publication}

Not applicable.

\section{Ethics approval and consent to participate}

Not applicable.

\section{Publisher's Note}

Springer Nature remains neutral with regard to jurisdictional claims in published maps and institutional affiliations.

\begin{abstract}
Author details
'Department of Anatomical and Cellular Pathology, State Key Laboratory in Oncology in South China, Prince of Wales Hospital, The Chinese University of Hong Kong, Hong Kong, SAR, People's Republic of China. ${ }^{2}$ Partner State Key Laboratory of Digestive Disease, Institute of Digestive Disease, The Chinese University of Hong Kong, Hong Kong, SAR, People's Republic of China. ${ }^{3}$ Sir Y.K. Pao Cancer Center, Li Ka Shing Institute of Health Science, The Chinese University of Hong Kong, Hong Kong, SAR, People's Republic of China. ${ }^{4}$ Shenzhen Research Institute, The Chinese University of Hong Kong, Shenzhen, People's Republic of China. ${ }^{5}$ Department of Gastroenterology, The Affiliated Drum Tower Hospital of Nanjing University, Medical School, Nanjing, People's Republic of China. ${ }^{6}$ Department of Anaesthesia and Intensive Care, The Chinese University of Hong Kong, Hong Kong, SAR, People's Republic of China. ${ }^{7}$ School of Biomedical Sciences, The Chinese University of Hong Kong, Hong Kong, SAR, People's Republic of China. ${ }^{8}$ Department of Medicine and Therapeutics, The Chinese University of Hong Kong, Hong Kong, SAR, People's Republic of China.
\end{abstract}

Received: 22 November 2016 Accepted: 4 April 2017

Published online: 11 April 2017

\section{References}

1. Torre LA, Bray F, Siegel RL, Ferlay J, Lortet-Tieulent J, Jemal A. Global cancer statistics, 2012. CA Cancer J Clin. 2015;65:87-108.

2. Kelley JR, Duggan JM. Gastric cancer epidemiology and risk factors. J Clin Epidemiol. 2003:56:1-9.

3. Lauren P. The Two Histological Main Types of Gastric Carcinoma: Diffuse and So-Called Intestinal-Type Carcinoma. An Attempt at a Histo-Clinical Classification. Acta Pathol Microbiol Scand. 1965;64:31-49.

4. Flejou JF. WHO Classification of digestive tumors: the fourth edition. Ann Pathol. 2011;31:S27-31.

5. The Cancer Genome Atlas Research N. Comprehensive molecular characterization of gastric adenocarcinoma. Nature. 2014;513:202-9.

6. Müeller-Pillasch F, Lacher U, Wallrapp C, Micha A, Zimmerhackl F, Hameister $H$, Varga $G$, Friess $H$, Büchler $M$, Beger $H G$, et al. Cloning of a gene highly overexpressed in cancer coding for a novel $\mathrm{KH}$-domain containing protein. Oncogene. 1997:14:2729-33.

7. Clauditz TS, Wang CJ, Gontarewicz A, Blessmann M, Tennstedt P, Borgmann K, Tribius S, Sauter G, Dalchow C, Knecht R, et al. Expression of insulin-like growth factor II mRNA-binding protein 3 in squamous cell carcinomas of the head and neck. J Oral Pathol Med. 2013;42:125-32.

8. Wang T, Fan L, Watanabe Y, Mcneill PD, Moulton GG, Bangur C, Fanger GR, Okada M, Inoue Y, Persing DH, Reed SG. L523S, an RNA-binding protein as a potential therapeutic target for lung cancer. Br J Cancer. 2003;88:887-94.

9. Pryor JG, Bourne PA, Yang Q, Spaulding BO, Scott GA, Xu H. IMP-3 is a novel progression marker in malignant melanoma. Mod Pathol. 2008;21:431-7.

10. Li D, Yan D, Tang H, Zhou C, Fan J, Li S, Wang X, Xia J, Huang F, Qiu G, Peng Z. IMP3 is a novel prognostic marker that correlates with colon cancer progression and pathogenesis. Ann Surg Oncol. 2009;16:3499-506.
11. Jeng YM, Chang CC, Hu FC, Chou HY, Kao HL, Wang TH, Hsu HC. RNAbinding protein insulin-like growth factor II mRNA-binding protein 3 expression promotes tumor invasion and predicts early recurrence and poor prognosis in hepatocellular carcinoma. Hepatology. 2008;48:1118-27.

12. Lochhead P, Imamura Y, Morikawa T, Kuchiba A, Yamauchi M, Liao X, Qian ZR, Nishihara R, Wu K, Meyerhardt JA, et al. IGF2BP3 (IMP3) expression is a marker of unfavourable prognosis in colorectal cancer. Eur J Cancer. 2012; 48:3405-13.

13. Kim HJ, Kim GE, Lee JS, Lee JH, Nam JH, Choi C. Insulin-like growth factor-II mRNA-binding protein 3 expression in effusion cytology: a marker for metastatic adenocarcinoma cells and a potential prognostic indicator in gastric adenocarcinoma. Acta Cytol. 2014;58:167-73.

14. He L, Hannon GJ. MicroRNAs: small RNAs with a big role in gene regulation. Nat Rev Genet. 2004;5:522-31.

15. Lu J, Getz G, Miska EA, Alvarez-Saavedra E, Lamb J, Peck D, Sweet-Cordero A, Ebert BL, Mak RH, Ferrando AA, et al. MicroRNA expression profiles classify human cancers. Nature. 2005:435:834-8.

16. Croce CM. Causes and consequences of microRNA dysregulation in cancer. Nat Rev Genet. 2009;10:704-14.

17. Jansson MD, Lund AH. MicroRNA and cancer. Mol Oncol. 2012;6:590-610.

18. Huang T, Kang W, Zhang B, Wu F, Dong Y, Tong JH, Yang W, Zhou Y, Zhang L, Cheng AS, et al. miR-508-3p concordantly silences NFKB1 and RELA to inactivate canonical NF-kappaB signaling in gastric carcinogenesis. Mol Cancer. 2016;15:9.

19. Kang W, Tong JH, Lung RW, Dong Y, Yang W, Pan Y, Lau KM, Yu J, Cheng AS, To KF. let-7b/g silencing activates AKT signaling to promote gastric carcinogenesis. J Transl Med. 2014;12:281.

20. Kang W, Tong JH, Chan AW, Lee TL, Lung RW, Leung PP, So KK, Wu K, Fan $D, Y u J$, et al. Yes-associated protein 1 exhibits oncogenic property in gastric cancer and its nuclear accumulation associates with poor prognosis. Clin Cancer Res. 2011;17:2130-9.

21. Kang W, Tong JH, Chan AW, Zhao J, Dong Y, Wang S, Yang W, Sin FM, Ng $\mathrm{SS}, \mathrm{Yu}$ J, et al. Yin Yang 1 contributes to gastric carcinogenesis and its nuclear expression correlates with shorter survival in patients with early stage gastric adenocarcinoma. J Transl Med. 2014;12:80.

22. Wong QW, Lung RW, Law PT, Lai PB, Chan KY, To KF, Wong N. MicroRNA223 is commonly repressed in hepatocellular carcinoma and potentiates expression of Stathmin1. Gastroenterology. 2008;135:257-69.

23. Zehentmayr F, Hauser-Kronberger C, Zellinger B, Hlubek F, Schuster C, Bodenhofer U, Fastner G, Deutschmann H, Steininger P, Reitsamer R, et al. Hsa-miR-375 is a predictor of local control in early stage breast cancer. Clin Epigenetics. 2016;8:28.

24. Kang W, Tong JH, Lung RW, Dong Y, Zhao J, Liang Q, Zhang L, Pan Y, Yang W, Pang JC, et al. Targeting of YAP1 by microRNA-15a and microRNA-16-1 exerts tumor suppressor function in gastric adenocarcinoma. Mol Cancer. 2015;14:52.

25. Shin G, Kang TW, Yang S, Baek SJ, Jeong YS, Kim SY. GENT: gene expression database of normal and tumor tissues. Cancer Inform. 2011;10:149-57.

26. Zhang X, Ni Z, Duan Z, Xin Z, Wang H, Tan J, Wang G, Li F. Overexpression of E2F mRNAs associated with gastric cancer progression identified by the transcription factor and miRNA co-regulatory network analysis. Plos One. 2015;10:e0116979.

27. Gao J, Aksoy BA, Dogrusoz U, Dresdner G, Gross B, Sumer SO, Sun Y,

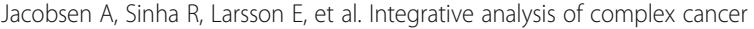
genomics and clinical profiles using the CBioPortal. Sci Signal. 2013;6:1.

28. Cerami E, Gao J, Dogrusoz U, Gross BE, Sumer SO, Aksoy BA, Jacobsen A, Byrne CJ, Heuer ML, Larsson E, et al. The cBio cancer genomics portal: an open platform for exploring multidimensional cancer genomics data. Cancer Discov. 2012;2:401-4.

29. Gyorffy B, Surowiak P, Budczies J, Lanczky A. Online survival analysis software to assess the prognostic value of biomarkers using transcriptomic data in non-small-cell lung cancer. Plos One. 2013;8:e82241.

30. Cristescu R, Lee J, Nebozhyn M, Kim KM, Ting JC, Wong SS, Liu J, Yue YG, Wang J, Yu K, et al. Molecular analysis of gastric cancer identifies subtypes associated with distinct clinical outcomes. Nat Med. 2015;21:449-56.

31. Liu BH, Goh CH, Ooi LL, Hui KM. Identification of unique and common low abundance tumour-specific transcripts by suppression subtractive hybridization and oligonucleotide probe array analysis. Oncogene. 2008;27:4128-36.

32. Chiang DY, Villanueva A, Hoshida Y, Peix J, Newell P, Minguez B, Leblanc AC, Donovan DJ, Thung SN, Sole M, et al. Focal gains of VEGFA and molecular classification of hepatocellular carcinoma. Cancer Res. 2008;68:6779-88. 
33. Ashburner M, Ball CA, Blake JA, Botstein D, Butler H, Cherry JM, Davis AP, Dolinski K, Dwight SS, Eppig JT, et al. Gene ontology: tool for the unification of biology. The Gene Ontology Consortium. Nat Genet. 2000;25:25-9.

34. Gene Ontology C. Gene Ontology Consortium: going forward. Nucleic Acids Res. 2015:43:D1049-56.

35. Kolesnikov N, Hastings E, Keays M, Melnichuk O, Tang YA, Williams E, Dylag M, Kurbatova N, Brandizi M, Burdett T, et al. ArrayExpress update-simplifying data submissions. Nucleic Acids Res. 2015;43:D1113-6.

36. Anaya J. OncoLnc: Linking TCGA survival data to mRNAs, miRNAs, and IncRNAs. Peer J Pre Prints. 2016:4:e1780v-1v.

37. Bell $J$, Wächter K, Mühleck B, Pazaitis N, Köhn M, Lederer M, Hüttelmaier S. Insulin-like growth factor 2 mRNA-binding proteins (IGF2BPs): posttranscriptional drivers of cancer progression? Cell Mol Life Sci. 2012;70:2657-75.

38. Wachter K, Kohn M, Stohr N, Huttelmaier S. Subcellular localization and RNP formation of IGF2BPs (IGF2 mRNA-binding proteins) is modulated by distinct RNA-binding domains. Biol Chem. 2013;394:1077-90.

39. Ueki A, Shimizu T, Masuda K, Yamaguchi SI, Ishikawa T, Sugihara E, Onishi N, Kuninaka S, Miyoshi K, Muto A, et al. Up-regulation of Imp3 confers in vivo tumorigenicity on murine osteosarcoma cells. Plos One. 2012;7:e50621.

40. Findeis-Hosey JJ, Xu H. The use of insulin like-growth factor II messenger RNA binding protein-3 in diagnostic pathology. Hum Pathol. 2011;42:303-14.

41. Suvasini R, Shruti B, Thota B, Shinde SV, Friedmann-Morvinski D, Nawaz Z, Prasanna KV, Thennarasu K, Hegde AS, Arivazhagan A, et al. Insulin growth factor-2 binding protein 3 (IGF2BP3) is a glioblastoma-specific marker that activates phosphatidylinositol 3-kinase/mitogen-activated protein kinase (PI3K) MAPK) pathways by modulating IGF-2. J Biol Chem. 2011;286:25882-90.

42. Rivera Vargas T, Boudoukha S, Simon A, Souidi M, Cuvellier S, Pinna G, Polesskaya A. Post-transcriptional regulation of cyclins D1, D3 and G1 and proliferation of human cancer cells depend on IMP-3 nuclear localization. Oncogene. 2014;33:2866-75.

43. Jonson L, Christiansen J, Hansen TV, Vikesa J, Yamamoto Y, Nielsen FC. IMP3 RNP safe houses prevent miRNA-directed HMGA2 mRNA decay in cancer and development. Cell Rep. 2014;7:539-51.

44. Samanta S, Sharma VM, Khan A, Mercurio AM. Regulation of IMP3 by EGFR signaling and repression by ERbeta: implications for triple-negative breast cancer. Oncogene. 2012;31:4689-97.

45. Samanta S, Pursell B, Mercurio AM. IMP3 protein promotes chemoresistance in breast cancer cells by regulating breast cancer resistance protein (ABCG2) expression. J Biol Chem. 2013;288:12569-73.

46. Okada K, Fujiwara Y, Nakamura Y, Takiguchi S, Nakajima K, Miyata H, Yamasaki M, Kurokawa Y, Takahashi T, Mori M, Doki Y. Oncofetal protein, IMP-3, a potential marker for prediction of postoperative peritoneal dissemination in gastric adenocarcinoma. J Surg Oncol. 2012;105:780-5.

47. Damasceno EA, Carneiro FP, Magalhaes AV, Carneiro Mde V, Takano GH, Vianna LM, Seidler HB, Castro TM, Muniz-Junqueira MI, Amorim RF, et al. IMP3 expression in gastric cancer: association with clinicopathological features and HER2 status. J Cancer Res Clin Oncol. 2014;140:2163-8.

48. Hermeking H. p53 enters the microRNA world. Cancer Cell. 2007;12:414-8.

49. Rottiers $\mathrm{V}$, Naar AM. MicroRNAs in metabolism and metabolic disorders. Nat Rev Mol Cell Biol. 2012;13:239-50

50. Misso G, Di Martino MT, De Rosa G, Faroogi AA, Lombardi A, Campani V, Zarone MR, Gulla A, Tagliaferri P, Tassone P, Caraglia M. Mir-34: a new weapon against cancer? Mol Ther Nucleic Acids. 2014;3:e194.

51. Han $Y$, Meng F, Venter J, Wu N, Wan $Y$, Standeford $H$, Francis $H$, Meininger C, Greene Jr J, Trzeciakowski JP, et al. miR-34a-dependent overexpression of Per1 decreases cholangiocarcinoma growth. J Hepatol. 2016;64:1295-304.

52. Bu P, Chen KY, Chen JH, Wang L, Walters J, Shin YJ, Goerger JP, Sun J, Witherspoon M, Rakhilin N, et al. A microRNA miR-34a-regulated bimodal switch targets Notch in colon cancer stem cells. Cell Stem Cell. 2013;12:602-15.

53. Gougelet A, Sartor C, Bachelot L, Godard C, Marchiol C, Renault G, Tores F, Nitschke P, Cavard C, Terris B, et al. Antitumour activity of an inhibitor of miR-34a in liver cancer with beta-catenin-mutations. Gut. 2016;65:1024-34.

54. Krzeszinski JY, Wei W, Huynh H, Jin Z, Wang X, Chang TC, Xie XJ, He L, Mangala LS, Lopez-Berestein G, et al. miR-34a blocks osteoporosis and bone metastasis by inhibiting osteoclastogenesis and Tgif2. Nature. 2014;512:431-5.

55. Cao W, Yang W, Fan R, Li H, Jiang J, Geng M, Jin Y, Wu Y. miR-34a regulates cisplatin-induce gastric cancer cell death by modulating PI3KJAKT/survivin pathway. Tumour Biol. 2014;35:1287-95.
56. Di Martino MT, Leone E, Amodio N, Foresta U, Lionetti M, Pitari MR, Cantafio ME, Gulla A, Conforti F, Morelli E, et al. Synthetic miR-34a mimics as a novel therapeutic agent for multiple myeloma: in vitro and in vivo evidence. Clin Cancer Res. 2012:18:6260-70.

57. Scognamiglio I, Di Martino MT, Campani V, Virgilio A, Galeone A, Gulla A, Gallo Cantafio ME, Misso G, Tagliaferri P, Tassone P, et al. Transferrinconjugated SNALPs encapsulating 2'-O-methylated miR-34a for the treatment of multiple myeloma. Biomed Res Int. 2014;2014:217365.

58. Di Martino MT, Campani V, Misso G, Gallo Cantafio ME, Gulla A, Foresta U, Guzzi PH, Castellano M, Grimaldi A, Gigantino V, et al. In vivo activity of miR34a mimics delivered by stable nucleic acid lipid particles (SNALPS) against multiple myeloma. Plos One. 2014;9:e90005.

\section{Submit your next manuscript to BioMed Central and we will help you at every step:}

- We accept pre-submission inquiries

- Our selector tool helps you to find the most relevant journal

- We provide round the clock customer support

- Convenient online submission

- Thorough peer review

- Inclusion in PubMed and all major indexing services

- Maximum visibility for your research

Submit your manuscript at www.biomedcentral.com/submit
) Biomed Central 